SITE 3 PART OF CHRYSE

Scale 1:250,000

HAROLD MASURSKY AND GEORGE W. COLTON

EXPLANATION

REGIONAL UNITS

\begin{tabular}{|l|}
\hline$s p$ \\
\hline$s p b$ \\
\hline$c h$ \\
\hline$c p$ \\
\hline$p I$ \\
\hline
\end{tabular}

smooth plains

smooth plains, bright

channel deposits, smooth

crater plumes, light

plateau material
CRATER UNITS

c crater material, undifferentiated

\begin{tabular}{|l|l|l|l|l|}
\hline$c r$ & $c w$ & $c f$ & $c c p$ & $c w f$ \\
\hline
\end{tabular}

cr - rim material

cw - wall material

cf - floor material

ccp - central peak material

cwf - wall \& floor material, undifferentiated

VOLCANIC UNITS

volcanic cone (prominent raised rim; obvious central depression)

\title{
LINE SYMBOLS
}

8

prominent rim crest

buried crater

scarp; barb points down slope

contact

L fault; bar and bell on downthrown side

$f$ shallow, channel-like trough

$\otimes$ closed or nearly closed depression

FE:

CENTE: 
SITE 3

Scale 1:1,000,000

N. J. TRASK

EXPLANATION

\section{c3}

Crater materials

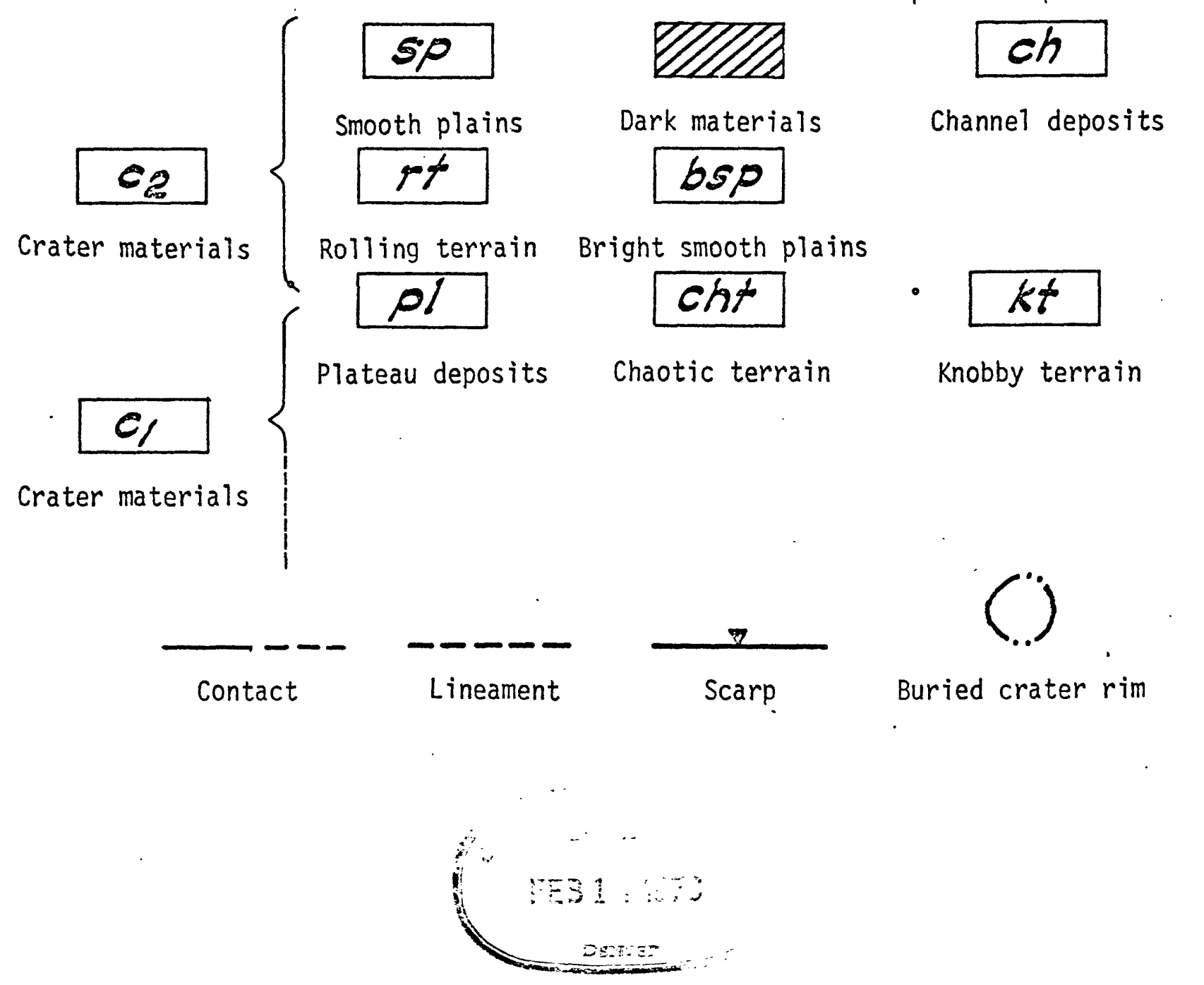

